\title{
Designing Shopping Area Atmospheric Using Choice-based Conjoint Analysis: Case Study at Soekarno-Hatta International Airport
}

\author{
Amalia Suzianti ${ }^{1}$ and Hutami Nadya Larasati ${ }^{2, a}$ \\ 1,2 Industrial Engineering Department, Faculty of Engineering, Universitas Indonesia, Depok, Indonesia
}

\begin{abstract}
As a response to overcapacity issue at Soekarno-Hatta International Airport, the government is recently planning on building larger terminal buildings to transport passengers. However, in designing an excellent terminal building, one should not only consider how to process passengers in the most efficient way, but also how facility-based environmental cues, or atmospheric cues, affect consumers' emotional state and shopping behavior. This research aims at examining passenger preferences towards atmospheric cues in airport shopping area and proposing a shopping area design based on consumer preferences. Choice-based conjoint was conducted towards 500 passengers at Soekarno-Hatta International Airport. Research findings suggested that there is a significant correlation between atmospheric cues and consumers' purchase intention in airport shopping area. Passengers prefer a shopping area with high in-store visibility, cool colors for window display, floors, wall, and ceiling, and bright lighting for airport hallway. This research also concludes that Socio-economic Status (SES) affects passengers' preferences.
\end{abstract}

\section{Introduction}

Among 189 airports operating in Indonesia, Soekarno-Hatta International Airport (SHIA) recorded the highest airport passenger traffic in Indonesia. SHIA occupies the $8^{\text {th }}$ position in world's busiest airports acording to Skytrax. However, SHIA was still ranked the $57^{\text {th }}$ for world's best airport according to Airports Council International. This indicates that passenger traffic in SHIA does not offset the service quality. In fact, according to DKMA, airport service quality may affect the airport's total commercial revenues. Airport commercial revenues are considered critical because they contribute to approximately $50 \%$ of total revenues, dominated by retail activities which account for $22 \%$ of total commercial revenues [1]. However, as the busiest airport in Indonesia, SHIA has not been able to achieve its commercial revenues target yet.

To overcome this issue, the government is planning to enlarge airport capacity both in terms of airfield and terminal building. However, to increase airport commercial revenues, passenger pleasure and arousal should be enhanced [2]. Empirical studies also suggest that atmosphere influence positive emotion then influence satisfaction and intention to purchase [3].

In Indonesia, airport terminal buildings were designed only to facilitate passengers flow as efficient as possible without considering other aspects that actually affect passengers' emotional state,

\footnotetext{
${ }^{a}$ Corresponding author : hutami.nadya@ui.ac.id
} 
such as atmospheric cues. Therefore, redesigning airport atmosphere based on consumer preferences becomes the key alternative to increase airport commercial revenues.

\section{Literature review}

\subsection{Atmospheric cues}

Kotler defined atmospheric as component of store image, including brightness and crowding [4]. Since then, research on consumer behavior was not only limited on how consumers respond to a product or service, but also on how consumers respond to environment. In the most recent model, atmospheric variables are classified into five categories: exterior variable, general interior variable, layout and design variables, point-of-purchase and decoration variables, and human variables [5].

External variables consist of a number of elements, such as storefront, marquee, window display, and parking area. General interior variables include flooring, wall textures, lighting, scent, music, temperature, cleanliness, and color [5]. Researches in psychophysiology showed that high wavelength or warm colors such as reds, oranges, and yellows, may have physiological effects opposite those of low wavelength or cool colors, such as blues, greens and whites [6]. Respondents perceived the $5000^{\circ} \mathrm{K}$ lighting as cool and the $3000^{\circ} \mathrm{K}$ lighting as warm [7]. Layout variables consist of traffic flow, allocation of product and the size of the store.

Product display can be defined as grouping of products, shelf space, allocation of floor space, department allocation, and wall decorations. Excellent product display should have, 1) attractive, creative, and systematic product display, 2) clear information on the products displayed, and 3) store design that allows consumers to see inside the store clearly from the outside.

\subsection{Choice-based conjoint analysis}

Choice-Based Conjoint (CBC) is an application of discrete choice modeling used to analyze consumer decision-making [8]. Discrete choice modeling was firstly introduced as a mathematical formula. Later, it was developed as a mathematical formula of discrete choice modeling with conjoint analysis.

$\mathrm{CBC}$ analysis also involves experimental design. Design of experiment is done to obtain profiles or combination of the attributes as well as choice sets that will be examined. The experimental design includes two assumptions that must be fulfilled. The first assumption is that the experimental design must be orthogonal. The second assumption is about the maximum number of tasks that should be tested. To maintain data reliability and prevent respondent fatigue of filling out the questionnaire, a CBC questionnaire should consist of no more than 20 sets of questions [9].

\section{Research methodology}

\subsection{Pilot study}

Pilot study was done by interviewing fifteen experts in order to determine atmospheric variables that may influence consumers purchase intention at an airport, including three professors of architecture and interior design, two practitioners in visual arts and interior design, and ten frequent fliers at SHIA.

The interview consisted of two parts. In the first part, interviewees were asked to categorize each atmospheric variable in the model into two categories. For each variable considered influential on consumer purchase intention at the airport, interviewees were asked to classify the variable as "important" and elaborate their answers, vice versa. After classifying each variable, interviewees proceeded to the second part of the interview, where they were asked to give rankings on atmospheric variables based on the level of importance.

From the interview conducted to fifteen interviewees, twenty different variables were considered influential on purchase intention at an airport. However, only eight variables intersected to one 
another. They are window display, store signage, cleanliness, product display, store entrance, product signage, color scheme, and lighting.

To clarify the level of agreement among experts, Kendall's W Test was carried out using SPSS. Result showed that level of agreement was acceptable (Kendall's W $=0.51$ ). Therefore, data obtained from previous pilot study could be used for the next step. The next step was to calculate the mean rank for each attribute using Friedman test. This test was performed by SPSS, aim to determine the attributes that will be examined, since $\mathrm{CBC}$ analysis should only examine not more than six attributes. Based on Table 1, it can be concluded that the six top-ranked attributes were window display, store signage, product display, store entrance, product signage and color schemes. However, after rechecking with the SHIA managers, store signage, cleanliness, and product signage were eleminated because they did not happen to be airport authority. Therefore, store signage and product signage were eliminated and replaced by lighting variable.

Table 1. Friedman Test Result

\begin{tabular}{cc}
\hline Friedman Test & Mean Rank \\
\hline window_display & 2,00 \\
store_signage & 2,13 \\
store_entrance & 5,37 \\
color_scheme & 5,50 \\
product_display & 3,40 \\
lighting & 5,53 \\
cleanliness & 6,67 \\
product_signage & 5,40 \\
\hline
\end{tabular}

Consequently, the result of the pilot study was five attributes as follows, window display, store entrance, color scheme, lighting, and product display. To prevent too many profiles and choice sets tested in the questionnaire, the number of levels was limited to two levels for each variable as shown in Table 2.

Table 2. Attributes and levels as applied in the questionnaire

\begin{tabular}{llll}
\multicolumn{1}{c}{ Attribute } & \multicolumn{1}{c}{ Level 1 } & \multicolumn{1}{c}{ Level 2 } & \multicolumn{1}{c}{ Source } \\
\hline Window Display & Cool colors & Warm colors & Somoon \& Sahachaisaree, 2012 \\
\hline Store Entrance & Using glass & Using no glass & William, 2002 \\
\hline Color Scheme & Warm colors & Cool colors & $\begin{array}{l}\text { Chebat\&Morrin, 2007 } \\
\text { Ballantine \& Jack, 2010 }\end{array}$ \\
\hline Product Display & $\begin{array}{l}\text { Products are visible from } \\
\text { outside the store }\end{array}$ & $\begin{array}{l}\text { Products are not visible } \\
\text { from outside the store }\end{array}$ & Hussain \& Ali, 2015 \\
\hline Lighting & Bright & Dim & Stemer, 2015 \\
\hline
\end{tabular}

\subsection{Main study}

The main study of this research includes analysis of consumer preferences using CBC method tested through questionnaire. In previous pilot study, the attributes and levels were all set. The next step was to do experimental design to obtain profile and choice sets that will be examined.

The researchers used a $1 / 4$ fractional factorial design, so the number of profiles obtained was 8 profiles with 16 choice sets, where each choice set consists of 2 pieces of alternative options. This experimental design was performed using XLSTAT software. 

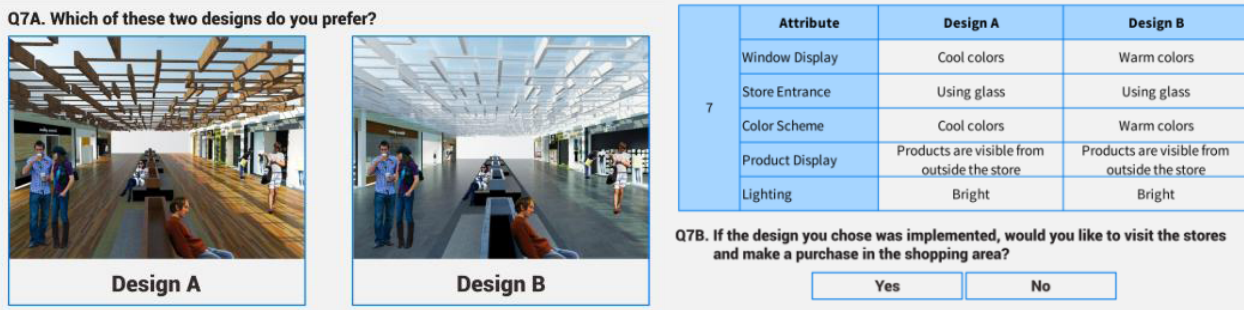

Figure 1. Choice-Based Conjoint Questionnaire Design

Figure 1 shows one of choice sets as applied in the questionnaire. Each choice set consists of two types of questions, namely Question A and Question B. Question A examines consumer preferences towards atmospheric design in airport shopping area. In Question A, respondents were asked to choose one out of two alternatives given in the pictures, in which each picture has different atmospheric characteristics. Meanwhile, Question B was intended to analyze the effect of atmospheric design on consumer purchase intention in airport shopping area. In this study, the population size refers to the number of passengers at SHIA. Using margin of errors 0.05 , it was calculated that the minimum sample size for this study was $399.96 \approx 400$ respondents.

\section{Results}

\subsection{Consumer preferences towards atmospheric design in airport terminal building}

The questionnaires were distributed to 795 respondents with $59 \%$ response rate, or in other words there were 500 respondents who completed the questionnaire, consisting of 262 women and 238 men. Data obtained from questionnaires were processed using XLSTAT software. The first analysis was utility value analysis that describes respondent preferences towards the attributes. Higher utility values imply respondent preferences. Table 3 shows the utility values for each attribute and level.

From data processing, it was concluded that respondents prefer window display design with cool colors, such as bluish-white. As for store entrance, respondents prefer a store entrance that uses glass compared to those that does not use glass although both are transparent. For color scheme variable, respondents prefer airport corridor design with cool colors, such as bluish-white, compared to warm colors, such as brown. The next attribute is product display or the level of convenience for consumers when viewing the products in the store from outside the store.

Table 3. Utility and importance values of each attributes

\begin{tabular}{|c|c|c|c|}
\hline Source & Utilities & Standard deviation & Importance \\
\hline Window Display-Cool colors & 0,028 & 0,021 & \multirow{2}{*}{2,259} \\
\hline Window Display-Warm colors & $-0,028$ & 0,021 & \\
\hline Store Entrance-Using glass & 0,012 & 0,017 & \multirow{2}{*}{0,984} \\
\hline Store Entrance-Using no glass & $-0,012$ & 0,017 & \\
\hline Color Scheme-Cool colors & 0,094 & 0,019 & \multirow{2}{*}{7,691} \\
\hline Color Scheme-Warm colors & $-0,094$ & 0,019 & \\
\hline Product Display-Products are visible from outside the store & 0,364 & 0,017 & \multirow{2}{*}{29,742} \\
\hline Product Display-Products are not visible from outside the store & $-0,364$ & 0,017 & \\
\hline Lighting-Dim & $-0,727$ & 0,019 & \multirow{2}{*}{59,324} \\
\hline Lighting-Bright & 0,727 & 0,019 & \\
\hline
\end{tabular}


The data obtained shows that the respondents prefer shopping area with products that are clearly visible from outside the store. The last attribute is the lighting, in which the respondents prefer the design of the airport shopping area with high intensity light. Among these five attributes, lighting variable has the highest importance value. In other words, lighting has the most influence on consumer preferences. Figure 2 shows the clear picture of the most preffered atmospheric characteristics of airport shopping area based on utility value analysis.

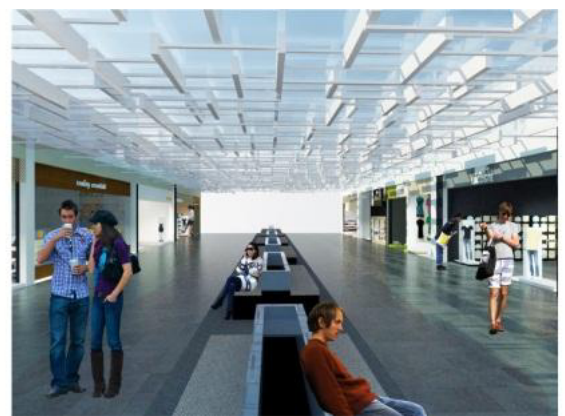

Figure 2. Consumer preferences towards atmospheric design in airport shopping area

\subsection{Correlation analysis between atmospheric design and purchase intention}

This analysis needs to be done to prove whether shopping area design can affect purchase intention. The analysis was performed with SPSS software using binomial logistic regression. The result of correlation analysis are presented in Table 4 . Since $p$ value $<0.05$, it can be concluded that the atmospheric design has a significant influence on consumer purchase intention at the airport.

Table 4. Correlation analysis between atmospheric design and purchase intention

\begin{tabular}{|ll|c|c|r|r|r|r|}
\hline & & B & S.E. & \multicolumn{1}{|c|}{ Wald } & df & Sig. & Exp(B) \\
\hline Step 1(a) & Profile &,- 112 &, 037 & 8,947 & 1 &, 003 &, 894 \\
& Constant & 1,839 &, 168 & 120,433 & 1 &, 000 & 6,291 \\
\hline
\end{tabular}

\subsection{Effects of Socio-economic Status towards consumer preferences}

According to consumer behavior theory, socio-economic class can affect consumer shopping behavior. Therefore, this analysis was conducted to determine whether there are differences on preferences between socioeconomic classes. The analysis was done using XLSTAT software to obtain the utility value of each attribute and level. The analysis was conducted for each socio-economic class divided by the Social Economy Status (SES), SES D, SES C, B SES, SES A, and SES A+.

As shown in Table 5, the findings indicate that each SES has different preferences on atmospheric design. Therefore, airport terminal building should be designed based on SES. By doing this, passengers will feel comfortable inside the terminal building and at the same time driving the passengers to shop at the airport.

\section{Conclusion}

Research was carried out by choice-based conjoint analysis. Survey was distributed to 500 passengers at SHIA, examining five variables including window display, store entrance, color scheme, product display, lighting. 
Table 5. Consumer preferences based on SES

\begin{tabular}{|c|c|c|c|c|}
\hline \multirow{2}{*}{ SES } & \multirow{2}{*}{ Monthly Expenditure } & \multicolumn{3}{|c|}{ Preference } \\
\hline & & Attribute & Level & Picture \\
\hline \multirow{5}{*}{$\mathrm{A}+$} & \multirow{5}{*}{ Above IDR5,000,000 } & Window Display & Warm colors & \\
\hline & & Store Entrance & Using glass & \\
\hline & & Color Scheme & Warm colors & \\
\hline & & Product Display & $\begin{array}{l}\text { Products are visible from the } \\
\text { outside }\end{array}$ & \\
\hline & & Lighting & Bright & \\
\hline \multirow{5}{*}{ A, B, C } & \multirow{5}{*}{$\begin{array}{l}\text { SES A (IDR } 3 \text { Mio-IDR } 5 \text { Mio) } \\
\text { SES B (IDR } 2 \text { Mio-IDR } 3 \text { Mio) } \\
\text { SES C (IDR } 1 \text { Mio-IDR } 2 \text { Mio) }\end{array}$} & Window Display & Cool colors & \\
\hline & & Store Entrance & Using glass & \\
\hline & & Color Scheme & Cool colors & \\
\hline & & Product Display & $\begin{array}{l}\text { Products are visible from the } \\
\text { outside }\end{array}$ & \\
\hline & & Lighting & Bright & \\
\hline \multirow{5}{*}{$\mathrm{D}$} & \multirow{5}{*}{ Below IDR I Mio } & Window Display & Warm colors & \\
\hline & & Store Entrance & No glass & \\
\hline & & Color Scheme & Cool colors & \\
\hline & & Product Display & $\begin{array}{l}\text { Products are visible from the } \\
\text { outside }\end{array}$ & \\
\hline & & Lighting & Bright & \\
\hline
\end{tabular}

Result showed that passangers prefer shopping area with cool colors, high level of store visibility, and high-intensity lighting (200 lx). Binomial logistic regression analysis showed that atmospheric variables significantly influence purchase intention at the airport.

This research also suggests that socioeconomic class influences consumer preferences. Results show that preferences between socioeconomic classes are slightly different to one another. In consequence, airport terminal building should be distinguished based on socioeconomic class.

\section{References}

1. P. Adey, "Airports, mobility and the calculative architecture of affective control,"Geoforum 39,pp. 438-451 (2008)

2. C. J. Oel and F. Berkhof, "Consumer Preferences in The Design of Airport Passenger Areas,"J. Env. Psy. 36, pp. 280-290 (2013)

3. S. Gunawan and V. H. Supit, "The Influence of Store Atmosphere on Emotional Responses and Re-Purchase Intention,” Bus. Manag. Strat.Vol.5 No.2 (2014)

4. P. Kotler, “Atmospherics as a Marketing Tool,”J. Retailing 49, pp. $48-64$ (1973)

5. L. W. Turley and R. E.Milliman, "Atmospheric Effects on Shopping Behavior: A Review of The Experimental Evidence,” J. Bus. Res. 49, pp. 193-211, 2000.

6. J. C. Chebat and M. Morrin, "Colors and Cultures: Exploring The Effects of Mall Decor on Consumer Perceptions,” J. Bus. Res. 60, pp.189-196 (2007)

7. N. K. Park and C. A. Farr, "The Effects of Lighting on Consumers' Emotions and Behavioral Intentions in a Retail Environment: A Cross-Cultural Comparison,'J. Interior Design 33, pp. 1732, 2007.

8. R. Grover and M. Vriens, "The Handbook of Marketing Research: Uses, Misuses, and Future Advances,” Thousand Oaks: Sage Publications, Inc. (2006)

9. R. M. Johnson and B. Orme, "Sawtooth Software: How Many Questions Should You Ask in Choice-Based Conjoint Studies," http://www.sawtoothsoftware.com (1996) 